\title{
Rate of pediatric tap water scald injuries in eastern Ontario
}

\author{
G Philip Barnsley $\mathrm{MD}^{1,2}$, Shannon E Barnsley MSc $\mathrm{MC}^{3,4}$
}

\begin{abstract}
GP Barnsley, SE Barnsley. Rate of pediatric tap water scald injuries in eastern Ontario. Can J Plast Surg 2007;15(1):33-37.
\end{abstract}

BACKGROUND: Tap water scalds can be devastating and are entirely preventable. This topic has received notable attention in Canada in recent years, with a national campaign in 2001 directed at parents recommending that they lower the water temperature of their home water heater. This campaign has been evaluated and reported as a successful population-based intervention.

OBJECTIVES: The present study evaluated the rate of pediatric tap water scalds in Ottawa, Ontario over the 10-year period from 1993 to 2002 in an attempt to identify the impact of this national awareness campaign.

METHODS: Data from the Children's Hospital of Eastern Ontario available in the Canadian Hospitals Injury Reporting and Prevention Program database were used to calculate the yearly incidence density of tap water scalds among children younger than 15 years in the city of Ottawa.

RESULTS: It was found that there was no statistically significant change in the rate of pediatric tap water scalds following the national campaign, and that the rate of these injuries was already very low ( 3.73 per 100,000 person-years over the study period). Of these, only $17 \%$ required observation or admission to hospital.

CONCLUSIONS: Given the low incidence of these injuries, their priority as a public health concern needs to be re-evaluated. If they continue to be a priority, new preventive strategies need to be used. It is thought that resources used to lobby for legislation of lower hot water temperatures may be more effective in reducing the incidence of these injuries.

Key Words: Burns; Injury; Pediatric; Prevention; Scalds

\section{Taux de brûlures pédiatriques causées par l'eau chaude du robinet dans l'Est de l'Ontario}

HISTORIQUE : Les brûlures causées par l'eau chaude du robinet peuvent être dévastatrices et elles sont tout à fait évitables. Cette question a passablement retenu l'attention au Canada ces dernières années, avec en 2001, une campagne nationale de sensibilisation à l'intention des parents, recommandant de réduire la température de l'eau des chauffe-eau domestiques. La campagne a fait l'objet d'une évaluation et selon les rapports, cette intervention auprès de la population a été efficace.

OBJECTIFS : La présente étude mesurait le taux de brûlures causées par l'eau chaude du robinet à Ottawa, Ontario, au cours d'une période de dix ans, soit de 1993 à 2002, pour tenter d'identifier l'impact de cette campagne nationale de sensibilisation.

MÉTHODES : Les données fournies par le Children's Hospital of Eastern Ontario, accessibles à partir de la base de données du Système canadien hospitalier d'information et de recherche en prévention des traumatismes, ont été utilisées pour calculer la densité de l'incidence annuelle des brûlures causées par l'eau chaude du robinet chez les enfants de moins de 15 ans dans la ville d'Ottawa.

RÉSULTATS : Les auteurs ont découvert qu'il n'y avait eu aucun changement statistiquement significatif du taux de brûlures causées par l'eau chaude du robinet chez les enfants après la campagne nationale et que le taux de ces blessures était déjà très faible (3,73 par 100000 annéespersonnes au cours de la période de l'étude). Parmi ces cas, $17 \%$ seulement ont nécessité une observation à l'hôpital ou une hospitalisation.

CONCLUSION : Compte tenu de la faible incidence de ces blessures, leur priorité à titre de problème de santé publique doit être réévaluée. Si elle demeure une priorité, de nouvelles stratégies préventives devront être utilisées. On estime que les ressources utilisées pour modifier la loi afin de réduire la température de l'eau des chauffe-eau domestiques pourraient faire diminuer plus efficacement l'incidence de ces blessures.
$\mathrm{B}$ urn injuries in children are serious and often result in long-term consequences, with both functional deficiencies and cosmetic deformities. Previous epidemiological studies have found that most burns in the pediatric population are from scalding (1-6), and a significant proportion of these scalds are from tap water. Some authors have stated that decreasing the temperature of hot water tanks in the home would have a significant effect on decreasing pediatric tap water scaldings $(7,8)$.

Moritz and Henriques (9) studied the exposure time required to produce deep second-degree burn wounds in different water temperatures. They found that in water with a temperature of $60^{\circ} \mathrm{C} \quad\left(140^{\circ} \mathrm{F}\right.$, usual domestic hot water temperature), the exposure required was $5 \mathrm{~s}$ to $6 \mathrm{~s}$. In water with a temperature of $49^{\circ} \mathrm{C}\left(120^{\circ} \mathrm{F}\right)$, the exposure time required was $9 \mathrm{~min}$. These data suggest that the incidence of scalding due to tap water would be significantly lowered, and perhaps abolished, by lowering the temperature of tap water by approximately $10^{\circ} \mathrm{C}$.

This concept has received notable attention in Canada in recent years. In 1997, Huyer and Corkum (7) published a thorough review of the evidence behind reducing the temperature of domestic hot water tanks to prevent pediatric scaldings. They outlined both active and passive prevention strategies; active prevention strategies included changing the behaviour of the public. The authors suggested that during patient visits, physicians should discuss the danger of hot tap water and identify steps that can be taken to reduce

${ }^{1}$ Department of Surgery, Division of Plastic Surgery, Dalhousie University, Halifax, Nova Scotia; ${ }^{2}$ Department of Epidemiology and Community

Medicine; ${ }^{3}$ School of Psychology, University of Ottawa, Ottawa, Ontario; ${ }^{4}$ Department of Clinical Psychology, IWK Health Centre, Halifax,

Nova Scotia

Correspondence: Dr Phil Barnsley, clo Dr Leif Sigurdson, Halifax Infirmary Room 4437, 1796 Summer Street, Halifax,

Nova Scotia B3H 3A7. Fax 902-473-8773, e-mail Barnsley@dal.ca 
the risk of scalding. They also recommended that parents be informed by their physician, or by pamphlets and posters in the waiting area, that young children should be supervised in the bathroom or kitchen at all times. Passive prevention strategies included altering the temperature of tap water through the legislation of lower water temperatures in home water heaters and the use of antiscald devices when higher water temperatures are required (7).

In 2001, Safe Kids Week 2001 - a national public awareness campaign run by Safe Kids Canada (8) - was introduced and highlighted the risks of tap water scalds. At a cost of approximately $\$ 600,000$, the information was propagated in the media, 5000 retail stores and 348 community partners throughout Canada. This program was later evaluated in a nationwide, random digit telephone survey, and was found to be successful in increasing knowledge and changing behaviour among parents (8). Moreover, parents who had been exposed to the messages of Safe Kids Week 2001 were more likely to report that they had checked the water temperature in their home and also were more likely to have reduced the temperature of the hot water heaters in their homes (8).

The impact of these two interventions on pediatric tap water scald rates are unknown. The goals of the present study were to provide a description of the epidemiology of pediatric burn injuries presenting to a tertiary care centre in Ontario over the 10-year period from 1993 to 2002 inclusive, and to determine the impact of Safe Kids Week 2001 on pediatric tap water scald rates. This will add to the understanding of the value of public interventions on the prevention of pediatric burn injuries, which will, in turn, improve future injury prevention strategies in Canada.

\section{METHODS}

The Canadian Hospitals Injury Reporting and Prevention Program (CHIRPP) database was used to identify all patients presenting to the Children's Hospital of Eastern Ontario (CHEO), a tertiary care hospital located in Ottawa, Ontario, over the 10-year period from 1993 to 2002 inclusive. CHEO serves the Champlain Health Region in Ontario, and a previous report found that $65 \%$ of pediatric injuries in this region present to this hospital (10). The remaining $35 \%$ of pediatric injuries presented to general hospitals in the region.

The CHIRPP database is a surveillance system administered by the Bureau of Chronic Disease Epidemiology within the federal government that began in 1990. This system is emergency departmentbased and involves a standardized collection form that is completed by both the parent and the treating physician. Information contained in the database includes patient demographic information as well as clinical information. The standardized forms are then sent to Ottawa for coding and entry into a central database (11). One of the fields within the database categorizes the mechanism of injury. Values of 40 to 49 represent chemical injuries, 50 to 59 represent thermal injuries and 60 to 69 represent electrical injuries. A study of the quality of CHIRPP data conducted in 1992 revealed the CHEO to have a much lower rate of injury reporting in the CHIRPP compared with other hospitals (11). The number of burn injuries reported to the CHIRPP from the $\mathrm{CHEO}$ in the following years increased dramatically (8433 observations with 111 burns in 1992 to 12,865 observations with 198 burns in 1993), and for this reason the study period in this investigation begins in 1993.
The data in the CHIRPP were analyzed using the SAS statistical package (SAS Institute, USA) to describe burn injuries in the region served by the $\mathrm{CHEO}$ among patients younger than 15 years of age. The frequencies of the various mechanisms of injury were examined to identify the proportion of burn injuries that include scalding and scalding by tap water. Scalding by tap water was identified in the 'Injury Event Description' field in each of the scald injuries in the database. This identification was performed by two independent observers, and the level of agreement was measured. The observations of disagreement were discussed following the independent review, and a decision as to whether the injury represents a tap water scald was made. The incidence density of pediatric burn injuries was calculated for the Champlain Health Region using census data from the 1996 and 2001 censuses to determine the person-years at risk. The intercensal population in Ottawa each year was logarithmically determined from the census figures. Because Statistics Canada provides information on the proportion of the population 15 years of age or younger in Ottawa in the 2001 census, this proportion was used to determine the person-years at risk in each year. A time series analysis was used to compare the incidence density of scald injuries occurring before and after the two interventions described.

\section{RESULTS}

During the study period, 1761 children younger than 15 years of age presented to the $\mathrm{CHEO}$ and were captured in the CHIRPP with burn-related injuries. A summary of these injuries is presented in Table 1. These injuries included 752 scald injuries (53\% of all thermal injuries). Of the total scald injuries, $72.2 \%$ occurred in children younger than five years of age, $5.5 \%$ required admission and $69.7 \%$ were treated on an outpatient basis. Scalds represented $42.3 \%$ of all admissions for burn injuries. When the 'Injury Event Description' field was analyzed, 52 tap water scalds were identified by one independent observer, and 56 by another (kappa=0.96). The five observations that were disagreements were then reviewed, and it was decided that two of these were tap water injuries and three were not. The descriptions of these injuries can be seen in Table 2 . This resulted in a total of 53 tap water scalds, representing $3.7 \%$ of all thermal injuries and $7.0 \%$ of all scald injuries (Table 3). Of these injuries, 15.1\% required admission, representing $8.2 \%$ of all burn-related admissions. The distribution of injury mechanism responsible for burn admissions is described in Table 4.

The population estimates for the city of Ottawa from the 1996 and 2001 censuses were obtained from Statistics Canada; these were 721,136 and 774,072, respectively. The 1991 estimate was adjusted by Statistics Canada to reflect the 2001 census boundaries. The population estimates for the remaining years were estimated using the intercensal logarithmic approach. In the 2001 census, $18.9 \%$ of the population was 15 years of age or younger. This proportion was used for all years of the study period, because yearly data were not available. The incidence densities of tap water scalds for each year in the study period appear in Figure 1.

When time series analysis was performed using autoregressive integrated moving average modelling, the intervention of Safe Kids Week 2001 was not associated with a statistically significant reduction in the number of pediatric tap water scalds $(\mathrm{P}=0.12)$. Caution is advised in interpreting this time series analysis, because it is based on a series of only 10 observations, and the $95 \%$ CIs for these observations are very wide, as seen 
TABLE 1

Descriptive statistics of all burn injuries captured during the 10-year study period from 1993 to 2002

\begin{tabular}{|c|c|c|}
\hline All burns & $\mathbf{n}$ & $\%$ \\
\hline Total & 1761 & 100.0 \\
\hline Chemical & 188 & 10.7 \\
\hline Electrical & 99 & 5.6 \\
\hline Thermal & 1418 & 80.5 \\
\hline Radiation & 56 & 3.2 \\
\hline \multicolumn{3}{|l|}{ Thermal injuries } \\
\hline Hot objects & 516 & 29.3 \\
\hline Open fire, flames or coals & 146 & 8.3 \\
\hline Hot liquids or steam & 752 & 42.7 \\
\hline Other heat & 4 & 0.2 \\
\hline \multicolumn{3}{|l|}{ Age groups, years } \\
\hline$<1$ & 219 & 12.5 \\
\hline 1 & 505 & 28.0 \\
\hline 2 to 4 & 471 & 26.7 \\
\hline 5 to 9 & 309 & 17.5 \\
\hline 10 to 14 & 257 & 14.6 \\
\hline \multicolumn{3}{|l|}{ Sex } \\
\hline Male & 1039 & 59.0 \\
\hline Female & 722 & 41.0 \\
\hline \multicolumn{3}{|l|}{ Disposition } \\
\hline Left without being seen & 25 & 1.4 \\
\hline Advice only & 149 & 8.5 \\
\hline Treated, follow-up as needed & 399 & 22.7 \\
\hline Treated, follow-up required & 1060 & 60.2 \\
\hline Short stay, observation in emergency department & 31 & 1.8 \\
\hline Admitted & 97 & 5.5 \\
\hline \multicolumn{3}{|l|}{ Intent of injury } \\
\hline Accident & 1742 & 98.9 \\
\hline Intentional self-harm & 2 & 0.1 \\
\hline Maltreatment by parent or caregiver & 5 & 0.3 \\
\hline Other unspecified assault & 1 & 0.1 \\
\hline Undetermined intent & 8 & 0.5 \\
\hline Assault or possible assault & 3 & 0.2 \\
\hline
\end{tabular}

TABLE 2

Description of observations that were disagreed on by individual reviewers and the final classification based on review by the two individual reviewers

\begin{tabular}{ll}
\hline Description of event & Final classification \\
\hline $\begin{array}{c}\text { Climbed onto counter, turned on hot water, } \\
\text { spilled hot water on thighs }\end{array}$ & Tap water scald
\end{tabular}

Was filling up hot water bottle, hot water bottle Tap water scald burst, scalded by hot water

Was playing, jumped into hot tub, water was too hot, scalds to both legs

Drank very hot water thinking it was cold water

Was standing in front of cupboards by sink, hot water spilled, resulting in scalds

in Figure 1. Also, the best autoregressive integrated moving average modelling model $(\mathrm{d}=1, \mathrm{p}=1, \mathrm{q}=0)$ for this series had an autocorrelation at lag1 with an absolute $t$ value of 1.38 , which
TABLE 3

Descriptive statistics of tap water scalds captured during the 10-year study period from 1993 to 2002

\begin{tabular}{lrr}
\hline Tap water scalds & $\mathbf{n}$ & $\%$ \\
\hline Age group, years & 14 & 26.4 \\
$<1$ & 17 & 32.1 \\
1 & 10 & 18.9 \\
2 to 4 & 8 & 15.1 \\
5 to 9 & 4 & 7.6 \\
10 to 14 & & \\
Sex & 25 & 47.2 \\
$\quad$ Male & 28 & 52.8 \\
Female & & \\
Disposition & 1 & 1.9 \\
Left without being seen & 3 & 5.7 \\
Advice only & 7 & 13.2 \\
Treated, follow-up as needed & 33 & 62.3 \\
Treated, follow-up required & 1 & 1.9 \\
Short stay, observation in emergency department & 8 & 15.1 \\
Admitted & & \\
Intent of injury & 50 & 94.3 \\
Accident & 1 & 1.9 \\
Maltreatment by parent or caregiver & 2 & 3.8 \\
Undetermined intent & & \\
\hline
\end{tabular}

TABLE 4

Burn injuries requiring admission by mechanism of injury

\begin{tabular}{lrr}
\hline Mechanism of injury & $\mathbf{n}$ & $\%$ \\
\hline Chemical & 8 & 8.2 \\
Thermal & 83 & 85.6 \\
$\quad$ Contact with hot objects & 9 & 9.3 \\
Contact with open fire, flames or coals & 33 & 34.0 \\
Contact with hot liquids or steam & 41 & 42.3 \\
Electrical & 5 & 5.2 \\
Sunburn & 1 & 1.0 \\
\hline
\end{tabular}

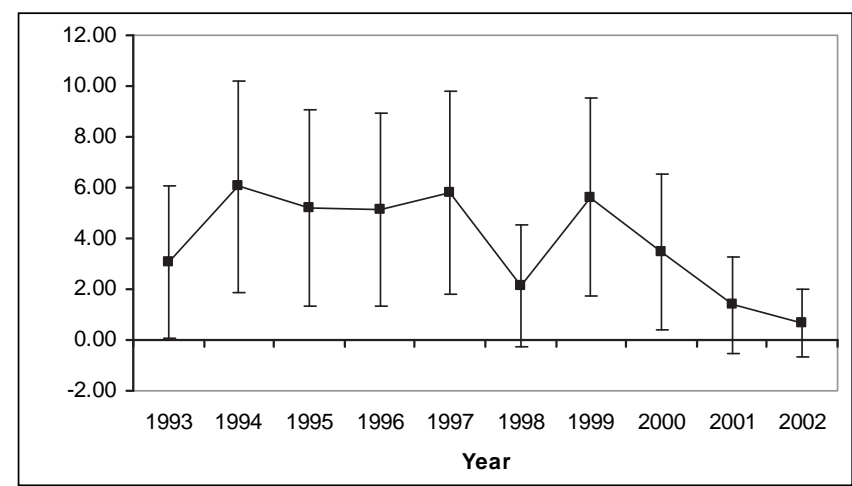

Figure 1) Incidence density of tap water scalds in Ottawa between 1993 and 2002 inclusive. Values are tap water scalds per 100,000 person-years at risk. Error bars represent 95\% CIs

is larger than the recommended value of 1.25 . This model includes both trend (the rate of tap water scalds is decreasing over time) and autoregression (the rate in one year depends in part on the rate in the previous year). 
TABLE 5

Comparison of injuries during the study period with other published data

\begin{tabular}{|c|c|c|c|c|c|c|c|c|}
\hline & $\begin{array}{l}\text { Barnsley and } \\
\text { Barnsley } \\
\text { present paper) }\end{array}$ & $\begin{array}{c}\text { Macarthur } \\
\text { (8) }\end{array}$ & $\begin{array}{c}\text { Fukunishi } \\
\text { et al (1) }\end{array}$ & $\begin{array}{l}\text { Silfen } \\
\text { et al (3) }\end{array}$ & $\begin{array}{c}\text { Ying and } \\
\text { Ho (4) }\end{array}$ & $\begin{array}{l}\text { Morrow } \\
\text { et al (5) }\end{array}$ & $\begin{array}{l}\text { Yamamoto and } \\
\text { Wiebe (6) }\end{array}$ & $\begin{array}{l}\text { Huyer and } \\
\text { Corkum (7) }\end{array}$ \\
\hline Per cent of burn injuries that are scalds & $42.7^{*}$ & 44 & & 58 & & Most common & & \\
\hline Per cent of burn admissions that are scalds & $42.3^{*}$ & 80 & & & 90.4 & & & \\
\hline Per cent of scalds that are from tap water & 7.0 & 10 to 15 & $\sim 50$ & & & & & \\
\hline Per cent of all burns that are from tap water & 3.0 & & & & & & $>50$ & \\
\hline Per cent of scalds requiring admission & 5.5 & & & & & & & 30 \\
\hline Per cent of admissions that are from tap water & 8.2 & & & & & & & 14 \\
\hline
\end{tabular}

${ }^{*}$ These were the most common mechanism. Approximately

\section{DISCUSSION}

In comparing the results of the present study with other published rates of pediatric burn injuries and scalds, the per cent of burn injuries that are scalds is consistent (Table 5). Huyer and Corkum (7) reported a much higher rate of admission for scald injuries, but a similar proportion of admissions that were a result of hot tap water. Interestingly, the proportions of tap water scalds in the Japanese studies are much higher than the studies from elsewhere in the world. This is consistent with the World Health Organization statement (12) that bathrelated burns are more frequent in Japan than in any other country, which has been attributed to their lifestyle and bathing systems.

The present study set out to find a reduction in the incidence of tap water scalds following two high-profile public health interventions. What was found was that the number of tap water scalds in the city of Ottawa was so low that this analysis could not be meaningfully performed. With an incidence density over the 10 -year study period of 3.73 per 100,000 person-years at risk ( $95 \%$ CI 2.72 to 4.75 ), one has to question whether this really is an important public health issue.

In 2001, Safe Kids Week was a national media campaign encouraging parents to lower the temperature of their hot water tanks, keep hot drinks away from children, check smoke alarms regularly and ensure their child's safety in the kitchen. This campaign cost an estimated $\$ 600,000$ to implement. In an evaluation of this program (8), random digit dialling was used to survey 504 households with children younger than nine years of age. It was found that $14 \%$ of these households recalled seeing, hearing or reading about scald and burn prevention during Safe Kids Week 2001. These households were considered the exposed group, and the others were considered the unexposed group. The survey determined that $6 \%$ of those in the exposed group and 2\% in the unexposed group lowered their water temperature following Safe Kids Week 2001, which was a statistically significant difference (RR 3.28, 95\% CI 1.09 to 9.90 ). Based on these findings, it was concluded that Safe Kids Week 2001 was an effective injury-prevention initiative.

This difference, despite being statistically significant, represents a risk difference of only $4 \%$ (95\% CI 0.6 to 7.7 ), meaning that $4 \%$ of the exposed population lowered their water temperature as a result of this campaign. If we make the assumptions that people who lower their water temperature are no longer at risk of tap water scald injury and that this intervention could reach the entire population (it only reached 14\% in Safe Kids Week
2001), this risk reduction would result in a decrease of tap water scalds from 3.73 per 100,000 person-years at risk to 3.58 per 100,000 person-years at risk in the city of Ottawa. Using the national data from 1990 to 1994 presented by Huyer and Corkum (7), this risk reduction would result in a decrease of tap water scalds from 50 to 48 per year, and a decrease in hospital admissions due to tap water scalds from 15 to 14 per year in all of Canada. Further, in considering the evaluation of Safe Kids Week 2001, the exposed and unexposed groups are questionable. This was a nationwide campaign, intended to reach the entire population, and in a pragmatic sense, the entire target population should be considered in the exposed group to measure how effective the program truly was.

Epidemiological research can provide objective information to identify priority public health issues. If, after considering the Canadian data describing pediatric tap water scalds, one still considers these injuries to be a high-priority pediatric public health issue, previously effective methods of lowering the incidence of these injuries need to be applied in Canada. Public health campaigns use a significant amount of resources in a time when resources are limited. There is a responsibility to use these resources in an effective manner and to address identified public health concerns.

Despite that the rate of tap water scald injuries is very low, they can be devastating, and they are preventable. When legislation was passed in Washington state, United States, that required new water heaters to be preset at $49^{\circ} \mathrm{C}\left(120^{\circ} \mathrm{F}\right)$, the admission rate for tap water scalds decreased from 5.5 per year in the 1970s to 2.4 per year in the 1980s (13). The arguments against this legislation have been previously discussed (7), and include dishwasher effectiveness and the risk of Legionella pneumophila infection in immunocompromised patients. The concern over dishwasher effectiveness centres around the occurrence of spotting when lower water temperatures are used, a minimal consequence if children are to be protected from tap water scalds. Immunocompromised patients and their physicians always need to be aware of risks of infection, and this awareness would prompt physicians to advise these patients to raise the temperature of their water heaters.

\section{CONCLUSIONS}

The rate of tap water scalds in the city of Ottawa over the past 10 years is very low at 3.73 per 100,000 person-years at risk. These and other data lead one to question the importance of this issue in a public health context, as well as the resources used in campaigns to lower this rate. Tap water scald injuries 
are entirely preventable; therefore, if this issue remains a public health priority, lobbying for legislative change may be a more effective use of resources to reduce the incidence of these injuries than attempts to prompt behavioural change in the general population.

ACKNOWLEDGEMENTS: The authors thank Morag MacKay, Director of Plan-it Safe, CHEO, for her assistance with the CHIRPP database; and Dr C van Walraven for his guidance in preparing the manuscript.

\section{REFERENCES}

1. Fukunishi K, Takahashi H, Kitagishi H, et al. Epidemiology of childhood burns in the critical care medical center of Kinki University Hospital in Osaka, Japan. Burns 2000;26:465-9.

2. Mercier C, Blond MH. Epidemiological survey of childhood burn injuries in France. Burns 1996;22:29-34.

3. Silfen R, Chemo-Lotan M, Amir A, Hauben DJ. Profile of the pediatric burn patient at the Schneider Children's Medical Center of Israel. Isr Med Assoc J 2000;2:138-41.
4. Ying SY, Ho WS. An analysis of 550 hospitalized pediatric burn patients in Hong Kong. J Burn Care Rehabil 2001;22:228-31.

5. Morrow SE, Smith DL, Cairns BA, Howell PD, Nakayama DK, Peterson HD. Etiology and outcome of pediatric burns. J Pediatr Surg 1996;31:329-33.

6. Yamamoto LG, Wiebe RA. Survey of childhood burns in Hawaii. Pediatr Emerg Care 1985;1:120-2.

7. Huyer DW, Corkum SH. Reducing the incidence of tap-water scalds: Strategies for physicians. CMAJ 1997;156:841-4.

8. Macarthur C. Evaluation of Safe Kids Week 2001: Prevention of scald and burn injuries in young children. Inj Prev 2003;9:112-6.

9. Moritz AR, Henriques FC. Studies of thermal energy: The relative importance of time and surface temperature in the causation of cutaneous burns. Am J Pathol 1947;23:695-720.

10. Macarthur C, Pless IB. Sensitivity and representativeness of a childhood injury surveillance system. Inj Prev 1999;5:214-6.

11. Macarthur C, Pless IB. Evaluation of the quality of an injury surveillance system. Am J Epidemiol 1999;149:586-92.

12. World Health Organization. Facts About Injuries: Burns. $<$ http://www.who.int/violence_injury_prevention/media/en/116.pdf> (Version current at November 28, 2006).

13. Erdmann TC, Feldman KW, Rivara FP, Heimbach DM, Wall HA. Tap water burn prevention: The effect of legislation. Pediatrics 1991;88:572-7. 